\title{
Morphological analysis of posterior malleolar fractures with intra-articular impacted fragment in computed tomography scans
}

Wenyong Xie ${ }^{1 \dagger}$, Hao Lu ${ }^{1 \dagger}$, Hailin Xu' ${ }^{1 \dagger}$, Yuan Quan ${ }^{1}$, Yijun Liu' ${ }^{1}$, Zhongguo Fu', Dianying Zhang ${ }^{1}$ and Baoguo Jiang ${ }^{1,2,3^{*}}$

\begin{abstract}
Background: Intraarticular impacted fragment (IAIF) of posterior malleolar fractures has been reported by a few studies. However its location, morphology, and the correlation of posterior malleolar fractures have not been described in detail. The aim of this study was to describe the morphology of IAIF in posterior malleolar fractures, to analyze the related factors between IAIF and posterior malleolar fragments, and explore the treatment of IAIF.
\end{abstract}

Materials and methods: Between January 2013 and December 2018, 108 consecutive patients with unilateral posterior malleolar fractures were managed in our hospital. Basic demographic and computed tomography (CT) data were collected and classified by Lauge-Hansen, OTA/AO, Haraguchi, and Mason classification. Additional radiographic data, including the length and area of posterior malleolar fragment, IAIF, and stable tibial plafond were measured. The location of IAIF was described, and involvement of the fibular notch and medial malleolus was also observed. Statistics were analyzed based on univariate analysis (Chi-square test, $t$-test, Mann-Whitney $U$ test, Fisher's test) and Spearman's correlation test.

Results: Among the 108 cases of posterior malleolar fractures, 75 (69.4\%) were with IAIF and 33 (30.6\%) cases were without. There were 74 (68.5\%) females and 34 (31.5\%) males, and the average age of the patients was 49 years (18-89 years). The average $L_{\text {IFN }} /\left(L_{\text {IFN }}+L_{S F N}\right)$ [length of involving fibular notch/(length of involving fibular + length of stable notch fibular notch)] was $32.9 \%$ (11.6-64.9\%). The $A_{\text {PMF }} /\left(A_{\text {PMF }}+A_{\text {STP }}+A_{\text {IAIF }}\right.$ ) [area of posterior malleolar fragment/(area of posterior malleolar fragment + area of IAIF + area of stable tibial plafond)] and $A_{\text {IAIF }} / A_{\text {PMF }}$ (area of IAIF/ area of posterior malleolar fragment) were $13.1 \%$ (0.8-39.7\%) and 52.6\% (1.2-235.4\%), respectively. Involvement of medial malleolus (fracture line extended to medial malleolus, $P=0.022)$, involvement of fibular notch $(P=0.021), L_{\text {IFN }} /$ $\left(L_{\text {IFN }}+L_{\text {SFN }}\right)(P=0.037), L_{\text {MPMF }}(P=0.004)$, and $A_{\text {PMF }}$ were significantly related to the occurrence of IAIF.

Conclusion: Our research indicates a high incidence of IAIF in posterior malleolar fractures. All IAIFs were found in posterior malleolar, and the most common location was within the lateral area A. Posterior malleolar fracture lines that extend to medial malleolus or fibular notch herald the incidence of IAIF. $L_{\text {IFN }} /\left(L_{\text {IFN }}+L_{S F N}\right), L_{\text {MPMF }}$ and $A_{\text {PMF }}$ are also associated with the incidence of IAIF. CT scans are useful for posterior malleolar fractures to determine the occurrence of IAIF and make operational plans. Operation approach selection should be based on the morphology of posterior malleolar fragments and the location of IAIF.

\footnotetext{
*Correspondence: jiangbaoguo@vip.sina.com

tWenyong Xie, Hao Lu, and Hailin Xu contributed equally to this article

1 Department of Orthopedics and Trauma, Peking University People's

Hospital, Beijing 100044, China

Full list of author information is available at the end of the article
} 
Level of evidence: Level III, retrospective case analysis.

Keywords: Posterior malleolus, Ankle fractures, Intraarticular fractures, Impact

\section{Introduction}

Ankle fractures are commonly encountered, with 112187 cases per 100,000 people reported per year [1,2]. More than $40 \%$ of ankle fractures involve the posterior malleolus [3]. The classification, surgical indication, and fixation method of posterior malleolar fractures are the subject of increasing attention, but there is still no consensus on the treatment of posterior malleolar fractures [4-9]. The quality of reduction and fixation of posterior malleolar fractures is significant to the outcome of ankle fractures $[9,10]$.

Intraarticular impacted fragment (IAIF) in posterior malleolus could sometimes be identified on computed tomography $(\mathrm{CT})$ scans of ankle fractures [11]. IAIF was first described in distal radius fractures, namely die-punch fragment [12], which was also common in pilon fractures [6]. Recently, Sultan et al. [13] described the characteristics of intercalary fragment as the IAIF in posterior malleolar fractures, and classified as free, folded, and compressed. IAIF is a kind of articular surface fragment resulting from impact and compressive forces. IAIF of posterior malleolar fractures has been reported in a few studies, with worse treatment outcomes predicted with IAIF $[8-11,14]$. However, the location, morphology, and the correlation of ankle and posterior malleolar fractures classification of IAIF have not been described in detail.

The primary aim of this study is to describe the incidence, location, and morphology of IAIF of posterior malleolar fractures, and explore the related factors among IAIF and posterior malleolar fragments and fracture classifications.

\section{Methods}

\section{Patient cohort}

Institutional review board approval was obtained prior to initiation of this study.

We retrospectively analyzed 256 consecutive patients with ankle fractures from January 2013 and December 2018 at our institution. The inclusion criteria included the following: (1) patients had OTA/AO Type 44 fracture involving posterior malleolus [15], (2) patients had preoperative CT scans, and (3) patients underwent surgical treatment. Patients with (1) previous ankle surgery, (2) pathological fractures, (3) CT image with a slice thickness $>1 \mathrm{~mm}$, and (4) age $\leq 16$ years old were excluded.

\section{Demography}

A total of 108 patients were finally included in this study. The average age was 49 years (18-89 years). There were 74 (68.5\%) females and 34 (31.5\%) males. The right ankle was more commonly involved than the left [63 (58.3\%) right, 45 (41.7\%) left]. The ankle fractures were classified according to the Lauge-Hansen and OTA/AO classification systems $[16,17]$. The posterior malleolar fractures were classified according to the Haraguchi and Mason classification systems $[18,19]$ (Table 1 ).

\section{Image analysis}

CT data were loaded into Mimics software (V20.0, Materialize), in which the data measurements were made, such as length of the involving fibular notch, length of IAIF, length of major posterior malleolar fragments, displaced height of IAIF from articular surface, as well as area of IAIF, posterior malleolar fragments, and the stable plafond. All CT data were evaluated and measured by one experienced orthopedic doctor.

On the axial CT cut of the tibial plafond, crosssectional length and area were measured (Fig. 1): (1) tibiofibular syndesmosis axial (from tibial articular surface)-measured as the cross-sectional length of involved fibular notch $\left(L_{\text {IFN }}\right.$, length of involved fibular notch) and the stable fibular notch $\left(L_{\mathrm{SFN}}\right.$, length of stable fibular notch); (2) IAIF articular surface axial-measured as the cross-sectional length and area of IAIF ( $L_{\text {IAIF }}$, length of IAIF; $A_{\text {IAIF }}$, area of IAIF); (3) posterior malleolar fragment axial-measured as the cross-sectional area of posterior malleolar fragment $\left(A_{\mathrm{PMF}}\right.$, area of posterior malleolar fragment); (4) stable plafond axial-measured as the cross-sectional area of stable tibial plafond $\left(A_{\mathrm{STP}}\right.$, area of stable tibial plafond).

On the sagittal CT cut of the tibial plafond, length measurements were made (Fig. 2): (1) major posterior malleolar fragment sagittal-measured as the distance from the anterior edge to the posterior edge of major posterior malleolar fragment ( $L_{\mathrm{MPMF}}$, length of major posterior malleolar fragment); (2) tibial plafond sagittal-measured as the distance from the anterior edge of tibial plafond to the posterior edge of stable tibial plafond ( $L_{\text {STP }}$, length of stable tibial plafond); (3) IAIF sagittalmeasured as the displaced height of IAIF from articular surface ( $H_{\text {IAIF }}$, height of IAIF).

$$
\begin{gathered}
L_{\mathrm{IFN}} /\left(L_{\mathrm{IFN}}+L_{\mathrm{SFN}}\right), \\
A_{\mathrm{IAIF}} /\left(A_{\mathrm{PMF}}+A_{\mathrm{STP}}+A_{\mathrm{IAIF}}\right), \\
A_{\mathrm{IAIF}} / A_{\mathrm{PMF}}, \quad A_{\mathrm{PMF}} /\left(A_{\mathrm{PMF}}+A_{\mathrm{STP}}+A_{\mathrm{IAIF}}\right) \text { and } L_{\mathrm{MPMF}} /
\end{gathered}
$$


Table 1 Patient characteristics $(N=108)$

\begin{tabular}{|c|c|c|c|}
\hline Patient characteristics & Overall number (\%) & IAIF group number (\%) & $\begin{array}{l}\text { NIAIF group } \\
\text { number (\%) }\end{array}$ \\
\hline Age (years)* & $49(18-89)$ & $49(22-89)$ & $49(18-89)$ \\
\hline \multicolumn{4}{|l|}{$\operatorname{Sex}^{\mathrm{a}}$} \\
\hline Male & 34 & 20 & 14 \\
\hline Female & 74 & 55 & 19 \\
\hline \multicolumn{4}{|l|}{ Injury site ${ }^{a}$} \\
\hline Left & 45 & 32 & 13 \\
\hline Right & 63 & 43 & 20 \\
\hline \multicolumn{4}{|l|}{ Lauge-Hansen classification ${ }^{a}$} \\
\hline Pronation-abduction & 8 & $4(50)$ & $4(50)$ \\
\hline Pronation-external rotation & 15 & $11(73.3)$ & $4(26.7)$ \\
\hline Supination-external rotation & 85 & $60(70.6)$ & $25(29.4)$ \\
\hline \multicolumn{4}{|l|}{ OTA/AO classification ${ }^{\mathrm{a}}$} \\
\hline B & 86 & $61(70.9)$ & $25(29.1)$ \\
\hline$C$ & 15 & $10(66.7)$ & $5(33.3)$ \\
\hline \multicolumn{4}{|l|}{ Haraguchi classification ${ }^{a}$} \\
\hline 1 & 71 & $47(66.2)$ & $24(33.8)$ \\
\hline 2 & 25 & $22(88)$ & $3(12)$ \\
\hline 3 & 12 & $6(50)$ & $6(50)$ \\
\hline \multicolumn{4}{|l|}{ Mason classification ${ }^{\mathrm{a}}$} \\
\hline 1 & 12 & $6(50)$ & $6(50)$ \\
\hline $2 \mathrm{~A}$ & 71 & $47(66.2)$ & $24(33.8)$ \\
\hline $2 \mathrm{~B}$ & 22 & 20 (90.9) & $2(9.1)$ \\
\hline 3 & 3 & $2(66.7)$ & $1(33.3)$ \\
\hline
\end{tabular}

IAIF intraarticular impacted fragments, NIAIF no intraarticular impacted fragments

*Values are given as the mean, with the range in parentheses

a Percentage was the ratio between the two groups

$\left(L_{\mathrm{MPMF}}+L_{\mathrm{STP}}\right)$ were calculated. Whether posterior malleolar fractures were involved in the fibular notch and medial malleolus was observed.

To study the location of IAIF, we divided the posterior part of the tibial plafond into two parts by the midpoint of the posterior tibial edge and named the lateral area $\mathrm{A}$ and the medial area B (Fig. 3).

\section{Data analysis}

Patient characteristics were summarized as proportions and mean, with the range given in parentheses. Statistical analysis was performed using SPSS V23.0 (Chicago, IL, USA). The 108 cases were divided into two groups; IAIF and NIAIF (no intraarticular impacted fragments). Univariate binary logistic analysis was used to analyze the related factors such as age ( $>60$ years, $\leq 60$ years), gender, involvement of medial malleolus (fracture line extended to medial malleolus), involvement of fibular notch, ratio of fibular notch, length of major posterior malleolar fracture fragment, area of posterior malleolar fracture fragment, Haraguchi classification, and Mason classification between group IAIF and group NIAIF.
Spearman's correlation was performed to determine the correlation among the area of IAIF and other factors. Statistical significance was declared for $P<0.05$.

\section{Results}

According to the Lauge-Hansen classification system, 108 cases were classified as follows: 8 (7.4\%) pronationabduction (PAB), 15 (13.9\%) pronation-external rotation (PER), and 85 (78.7\%) supination-external rotation (SER). For the OTA/AO system, consensus classification demonstrated $86(85.1 \%)$ as B and $15(14.9 \%)$ as C. As for the Haraguchi classification, we determined that 71 (65.7\%) were type 1,25 (23.1\%) type 2 , and 12 (11.2\%) type 3. With the Mason classification, consensus classification demonstrated $12(11.2 \%)$ as type $1,71(65.7 \%)$ as type $2 \mathrm{~A}, 22(20.3 \%)$ as type $2 \mathrm{~B}$, and $3(2.8 \%)$ as type 3 . Of the 108 cases, we also compared the fracture classifications between cases with IAIF $(75,69.4 \%)$ and those without (33, 30.6\%) (Table 1).

Among the 108 cases, the fibular notch was involved in $89(82.4 \%)$ cases. Average $L_{\mathrm{IFN}} /\left(L_{\mathrm{IFN}}+L_{\mathrm{SFN}}\right)$ was $32.9 \%$ (11.6-64.9\%); average $L_{\mathrm{MPMF}}$ and $L_{\text {IAIF }}$ were $8.07 \mathrm{~mm}$ 


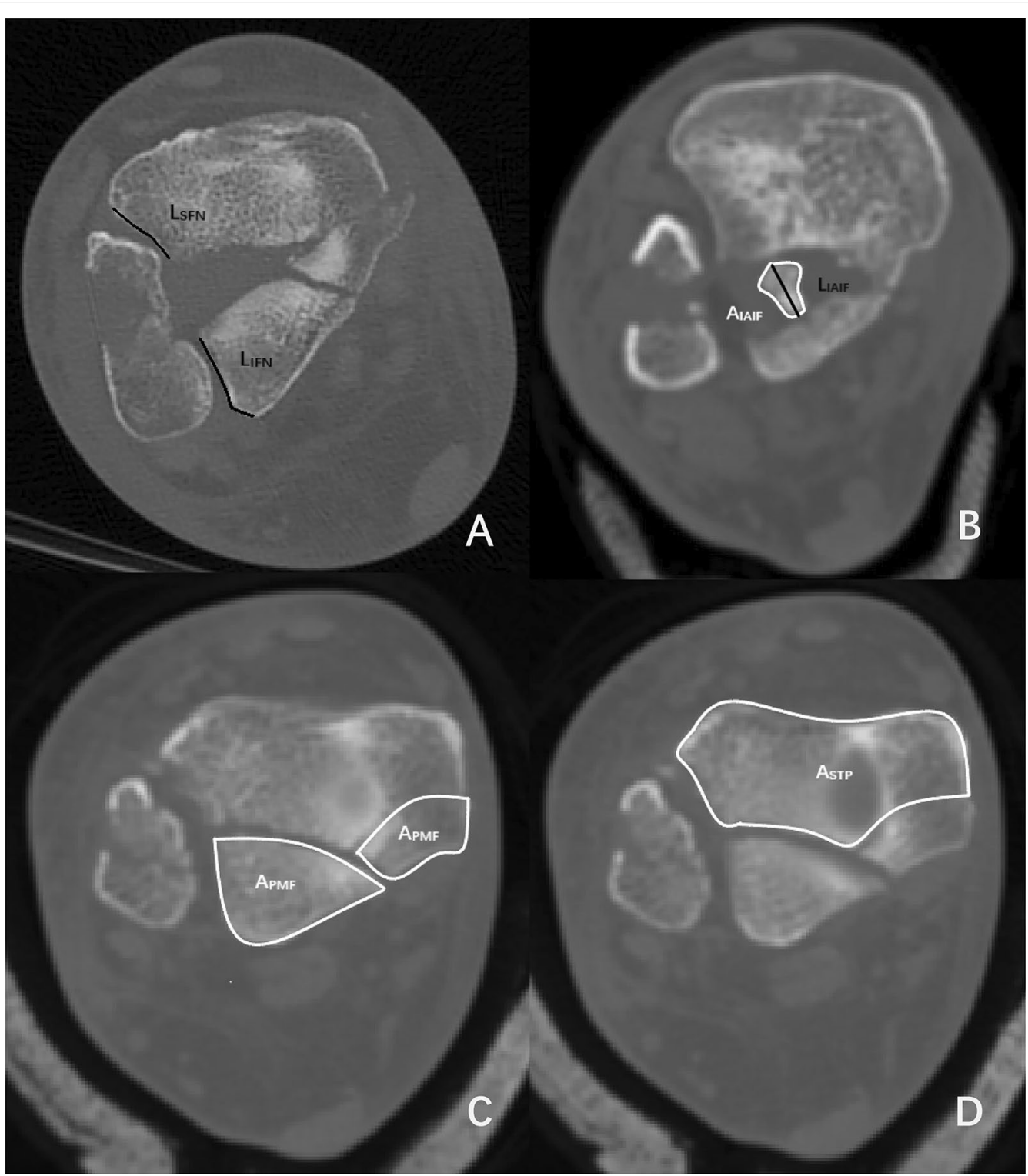

Fig. 1 Example axial CT cross-sectional measurements. A Measured as the length of involved fibular notch ( $L_{\mid F N}$ length of involved fibular notch) and the stable fibular notch ( $L_{S F N}$ length of stable fibular notch). B Measured as the length and area of IAIF ( $L_{\text {IAF, }}$ length of IAIF, black; $A_{\text {IAF, }}$ area of IAIF, white). C Measured as the area of posterior malleolar fragment ( $A_{\mathrm{PMF},}$ area of posterior malleolar fragment). D Measured as the area of stable tibial plafond ( $A_{S T P}$, area of stable tibial plafond)

$(0.8-25.74 \mathrm{~mm})$ and $6.17 \mathrm{~mm}(2.09-12.72 \mathrm{~mm})$, respectively. The average $H_{\text {IAIF }}$ was $2.91 \mathrm{~mm}(0.72-9.35 \mathrm{~mm})$. The average $A_{\mathrm{PMF}}$ was $172.64 \mathrm{~mm}^{2}\left(12.52-523.71 \mathrm{~mm}^{2}\right)$, that of $A_{\text {IAIF }}$ was $60.01 \mathrm{~mm}^{2}\left(4.87-199.94 \mathrm{~mm}^{2}\right)$, and $A_{\text {STP }}$ was $1101.28 \mathrm{~mm}^{2}\left(676.47-1701.83 \mathrm{~mm}^{2}\right)$. Therefore, $L_{\mathrm{MPMF}} /\left(L_{\mathrm{MPMF}}+L_{\mathrm{STP}}\right)$ was $20.8 \%(3.0-63.7 \%)$ on average. $A_{\mathrm{PMF}} /\left(A_{\mathrm{PMF}}+A_{\mathrm{STP}}+A_{\mathrm{IAIF}}\right)$ was $13.1 \%(0.8-39.7 \%)$ on average, that of $A_{\mathrm{IAIF}} /\left(A_{\mathrm{PMF}}+A_{\mathrm{STP}}+A_{\mathrm{IAIF}}\right)$ was $4.7 \%$ $(0.4-17.8 \%)$ and $A_{\mathrm{IAIF}} / A_{\mathrm{PMF}}$ was $52.6 \%(1.2-235.4 \%)$. There were $25(23.1 \%)$ cases of posterior malleolar fractures involving medial malleolus. The area of posteromedial fragments and posterolateral fragments of $23(21.3 \%)$ cases were measured separately. The average ratio of the posteromedial fragments to posterolateral fragments was $89.8 \%$ (8.75-189.6\%) (Table 2).

As for the location of IAIF, there were 75 (69.4\%) cases with IAIF. Sixty-five cases with single IAIF were distributed into $43(57.3 \%)$ cases in area A, $16(21.3 \%)$ cases in area $B$, and $6(8 \%)$ cases in the dividing line of area $A$ and $\mathrm{B}(\mathrm{A} \& \mathrm{~B})$. In the nine cases with two IAIFs, one $(1.3 \%)$ 

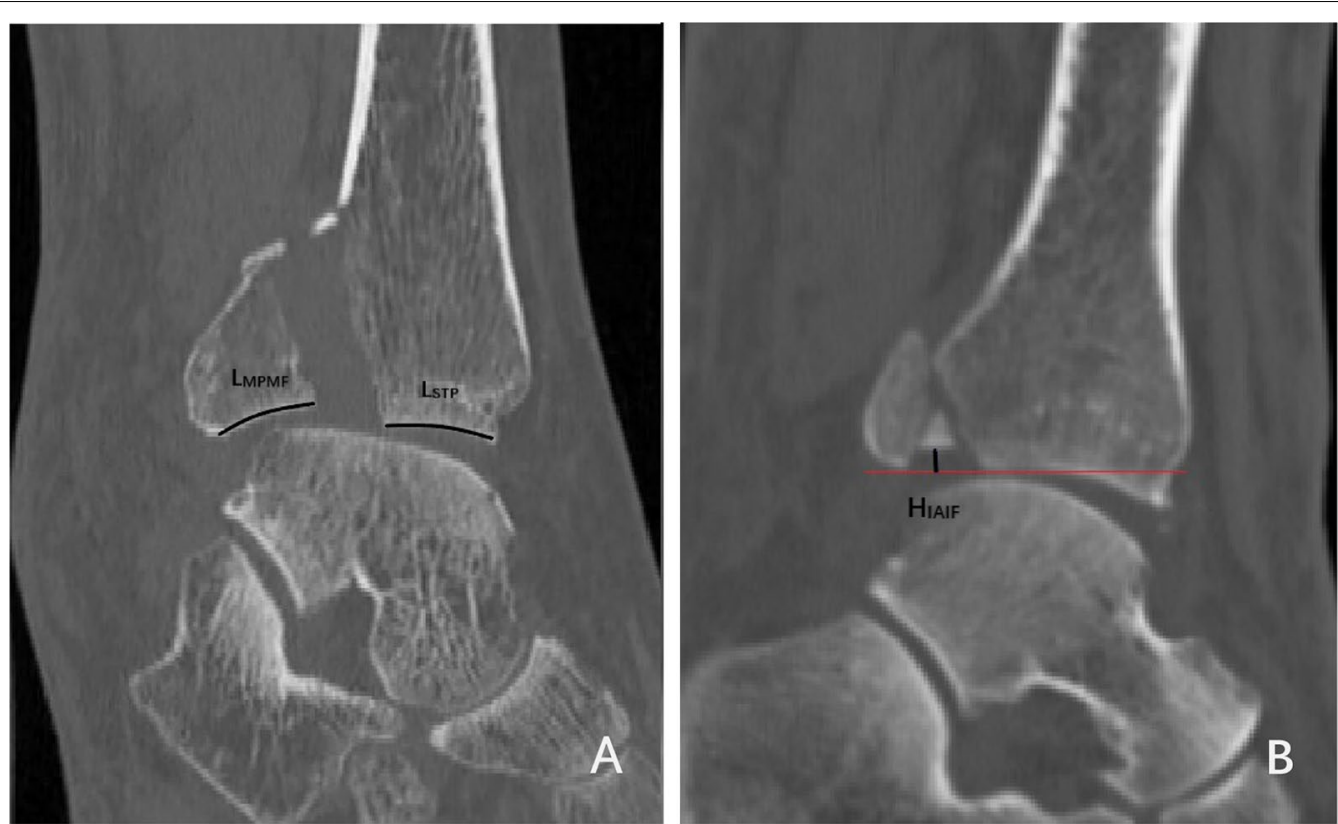

Fig. 2 Example sagittal CT linear measurements. A Measured as the length of major posterior malleolar fragment $\left(L_{\text {MPMF, }}\right.$ length of major posterior malleolar fragment) and stable tibial plafond ( $L_{S T P}$, length of stable tibial plafond). B Measured as the displaced height of IAIF ( $H_{I A \mid F,}$, height of IAIF) and the red line is the horizontal line of articular surface

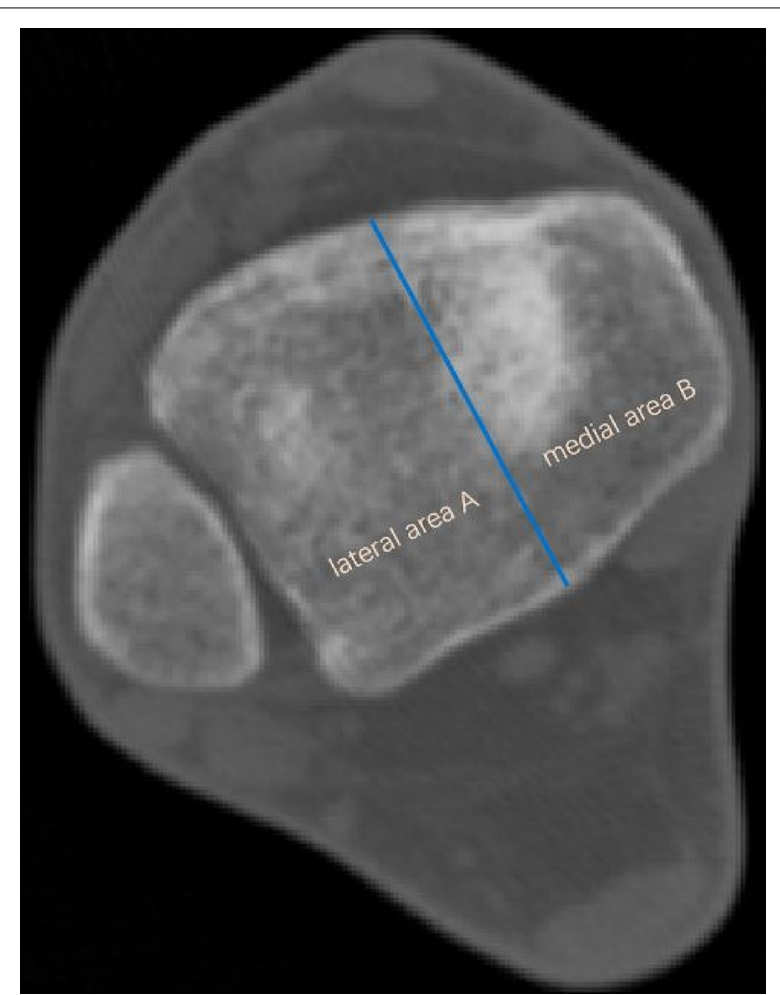

Fig. 3 Division of the tibial plafond: lateral area A and medial area B case was located in area A and eight (10.7\%) cases were located in both area A and B. There was one (1.3\%) case with three IAIFs, two of which were located in area A, with another one in area B (Table 3).

IAIF occurrence was significantly related with the involvement of medial malleolus (fracture line extended to medial malleolus, $P=0.022)$, the involvement of fibular notch $(P=0.021), L_{\mathrm{IFN}} /\left(L_{\mathrm{IFN}}+L_{\mathrm{SFN}}\right) \quad(P=0.037), L_{\mathrm{MPMF}}$ $(P=0.004), A_{\mathrm{PMF}}(P=0.010)$, Haraguchi classification $(P=0.037)$, and Mason classification $(P=0.038)$. There was no significant difference in the intragroup comparison of Haraguchi and Mason classification (Table 4). We further explored the correlation between $A_{\text {IAIF }}$ and $A_{\text {PMF }}$, $L_{\mathrm{MPMF}}, L_{\mathrm{IFN}}$, and age. The result showed that the $A_{\text {IAIF }}$ was irrelevant to the factors mentioned above (Table 5).

\section{Discussion}

There was a high incidence of IAIF in posterior malleolar fractures. Through the morphological analysis of posterior malleolar fractures on CT scans, 75 cases (69.4\%) of posterior malleolar fractures presented with IAIF, which was far beyond our expectations. CT scans are beneficial in identifying IAIF since most IAIF cannot be found by X-ray. More attentions should be paid to the size of the posterior malleolar fragments and its effect on ankle stability and contact stress [20-22].

In our study, $71(65.7 \%)$ cases of posterior malleolar fractures with single fragment could be classified as 
Table 2 Related measurement of posterior malleolar fractures

\begin{tabular}{|c|c|c|c|}
\hline & Length (mm) & Area $\left(\mathrm{mm}^{2}\right)$ & Ratio (\%) \\
\hline$L_{M P M F}$ & $8.07(0.8-25.74)$ & & \\
\hline IAIF & $6.17(2.09-12.72)$ & 60.01 (4.87-199.94) & \\
\hline$H_{\text {IAIF }}$ & $2.91(0.72-9.35)$ & & \\
\hline$A_{\text {PMF }}$ & & $172.64(12.52-523.71)$ & \\
\hline$L_{\text {IFN }}$ & $9.44(3.05-20.09)$ & & \\
\hline$L_{\text {IFN }} /\left(L_{\text {IFN }}+L_{\text {SFN }}\right)$ & & & $32.9(11.6-64.9)$ \\
\hline$L_{\mathrm{MPMF}} /\left(L_{\mathrm{MPMF}}+L_{\mathrm{STP}}\right)$ & & & $20.8(3.0-63.7)$ \\
\hline$A_{\mathrm{PMF}} /\left(A_{\mathrm{PMF}}+A_{\mathrm{STP}}+A_{\mathrm{IAIF}}\right)$ & & & $13.1(0.8-39.7)$ \\
\hline$A_{\text {IAIF }} /\left(A_{\mathrm{PMF}}+A_{\text {STP }}+A_{\mathrm{IAIF}}\right)$ & & & $4.7(0.4-17.8)$ \\
\hline$A_{\text {IAIF }} / A_{\text {PMF }}$ & & & $52.6(1.2-235.4)$ \\
\hline
\end{tabular}

Table 3 The numbers and location of IAIF

\begin{tabular}{llll}
\hline IAIF numbers & \multicolumn{2}{l}{ IAIF location } & \\
\cline { 2 - 4 } & A (\%) & B (\%) & A\&B (\%) \\
\hline 1 & $43(50 \%)$ & $16(18.6 \%)$ & $6(7 \%)$ \\
2 & $10(11.6 \%)$ & $8(9.3 \%)$ & 0 \\
3 & $2(2.3 \%)$ & $1(1.2 \%)$ & 0 \\
\hline
\end{tabular}

IAIF intraarticular impacted fragments
Haraguchi 1 or Mason 2A. IAIF was found in more than $2 / 3$ cases of single fragment fractures, and the average area of fragments was larger than those without IAIF. Haraguchi et al. [18] claimed type 1 was a posterior malleolar avulsion fracture, while Mason et al. [19] indicated type 2A was a "push-off" fracture (the loaded talus pushes off the posterolateral corner of the tibia). Due to the high incidence of IAIF in the single fragment, we

Table 4 Univariate analysis results for the relation of IAIF

\begin{tabular}{|c|c|c|c|c|}
\hline Variables & IAIF $(n=75)$ & NIAIF $(n=33)$ & Statistical values & $P$-Value \\
\hline Age (>60 years/ $\leq 60$ years) & $20 / 55$ & $12 / 21$ & 1.033 & $0.309^{a}$ \\
\hline Gender (Male/Female) & $20 / 55$ & $14 / 19$ & 2.638 & $0.104^{\mathrm{a}}$ \\
\hline Involvement of medial malleolus & $22 / 53$ & $3 / 30$ & 5.278 & $0.022^{\mathrm{a}}$ \\
\hline Involvement of fibular notch & $66 / 9$ & $23 / 10$ & 5.295 & $0.021^{\mathrm{a}}$ \\
\hline$L_{\mathrm{IFN}} /\left(L_{\mathrm{IFN}}+L_{\mathrm{SFN}}\right)^{*}$ & $0.27 \pm 0.13$ & $0.25 \pm 0.13$ & -2.115 & $0.037^{b}$ \\
\hline$L_{\text {MPMF }} \#$ & $7.30(1.89-25.74)$ & $5.40(0.80-16.10)$ & -2.868 & $0.004^{c}$ \\
\hline$A_{\mathrm{PMF}} \#$ & $147.15(12.96-523.71)$ & $95.60(12.52-466.17)$ & -2.438 & $0.010^{c}$ \\
\hline Haraguchi $(1 / 2 / 3)^{\S}$ & & & 6.569 & $0.037^{\mathrm{a}}$ \\
\hline 1 & 48 & 24 & & \\
\hline 2 & 21 & 3 & & \\
\hline 3 & 6 & 6 & & \\
\hline Mason $(1 / 2 \mathrm{~A} / 2 \mathrm{~B} / 3)^{\S}$ & & & 7.886 & $0.038^{\mathrm{a}}$ \\
\hline 1 & 6 & 6 & & \\
\hline $2 \mathrm{~A}$ & 47 & 24 & & \\
\hline $2 \mathrm{~B}$ & 20 & 2 & & \\
\hline 3 & 2 & 1 & & \\
\hline
\end{tabular}

IAIF intraarticular impacted fragments, NIAIF no intraarticular impacted fragments

*Values are given as the mean \pm SD

\# Values are given as the median, with the range in parentheses

${ }^{\S}$ Chi-square test of Haraguchi $(1 / 2 / 3)(P=0.037)$ and Mason $(1 / 2 \mathrm{~A} / 2 \mathrm{~B} / 3)(P=0.038)$. By pairwise comparison, there was no significant difference among the intragroup comparison in Haraguchi $(1 / 2 / 3)$ and Mason $(1 / 2 \mathrm{~A} / 2 \mathrm{~B} / 3)$ through Fisher's exact test

${ }^{\text {a }}$ Chi-square test

${ }^{\mathrm{b}} t$-test

${ }^{\mathrm{c}}$ Mann-Whitney $U$ test 
Table 5 Spearman correlation analysis for area of IAIF

\begin{tabular}{lll}
\hline & RS & P-Value $^{*}$ \\
\hline$A_{\text {IAIF }}$ and $A_{\text {PMF }}$ & -0.41 & 0.729 \\
$A_{\text {IAIF }}$ and $L_{\text {MPMF }}$ & -0.165 & 0.157 \\
$A_{\text {IAIF }}$ and $L_{\text {IFN }}$ & -0.230 & 0.063 \\
$A_{\text {IAIF }}$ and age & -0.110 & 0.348
\end{tabular}

${ }^{*} P<0.05$ assumed statistical significance, based on Spearman correlation analysis

speculate that the mechanisms of injury of single fragment fracture may include rotation impact, and not just avulsion fracture. The larger the posterior malleolar fragments, the higher the proportion of rotation impact.

There were $22(20.4 \%)$ cases of posterior malleolar fractures with multifragment that could be regarded as Haraguchi 2 or Mason 2B. Among the fractures, 20 cases (90.9\%) were found with IAIF, and 17 cases (77.3\%) of IAIF were distributed in medial area B (deep of posteromedial fragment). Mason et al. [19] believed the mechanism of Mason 2B was that the loaded talus pushes off the posterolateral corner of the tibia when rotated in the ankle mortise and with continued rotation, the posteromedial corner was also fractured as a separate fragment. Vosoughi et al. [23] studied Mason $2 \mathrm{~B}$, in which separate posteromedial fragment was associated with a posterolateral fragment in a rotational injury that included both supination external rotation (SER) and pronation external rotation (PER) injuries. Gardner et al. [24] supposed external rotation and hyperplantarflexion as the mechanism of multifragment. IAIF in multifragment fractures was primarily located in medial area B. We suppose the mechanism of multifragment fractures is consistent with the view of Mason.

An unexpected result was that $50 \%$ Haraguchi 3 fractures accompanied IAIF in $12(11.2 \%)$ cases of Haraguchi 3 (Mason 1) fractures. The Haraguchi 3 fracture is an inferior transverse tibiofibular ligament (deep fibers of posterior inferior tibiofibular ligament) avulsion fracture $[18,19]$, not as small as "bone chips." We believe it has been significantly underestimated in the current literature. Some IAIFs can be found in Haraguchi 3 fractures and can only be observed on CT scans. Attention should be paid to the posterior malleolar fractures, even the Haraguchi 3 fractures.

Almost all posterior malleolar fractures of Haraguchi 2 or Mason 2B involve the medial malleolus and fibular notch $[18,19]$. Through univariate analysis, it was found that the involvement of medial malleolus (fracture line extended to medial malleolus, $P=0.022$ ) was related to the incidence of IAIF. The fibular notch is very important for the stability of the ankle joints [25]. Fracture lines in $25(23.1 \%)$ cases in which the medial malleolus was involved had extended to the fibular notch. By univariate analysis, it was found that the involvement of fibular notch $(P=0.021)$ was also related to the incidence of IAIF. A total of 89 (82.4\%) cases involved fibular notch, and the $L_{\mathrm{IFN}} /\left(L_{\mathrm{IFN}}+L_{\mathrm{SFN}}\right)$ was $26.7 \%(9.4-62.9 \%)$ on average. Greater involvement of fibular notch and bigger posterior malleolar fragments are associated with higher incidence of IAIF.

Related measurement and calculation of the posterior malleolar fractures showed that the $A_{\text {IAIF }}$ was $60.01 \mathrm{~mm}^{2}$ $\left(4.87-199.94 \mathrm{~mm}^{2}\right)$ on average, and the $A_{\mathrm{IAIF}} / A_{\mathrm{PMF}}$ was $52.6 \%(1.2-235.4 \%)$. With an average ratio over $50 \%$, some IAIF are larger than posterior malleolar fragments. No correlation between the $A_{\text {IAIF }}$ and other factors, such as $A_{\mathrm{PMF}}, L_{\mathrm{MPMF}}, L_{\mathrm{IFN}}$, and age were found. In our study, some small posterior malleolar fragments with very large IAIF were identified, so IAIF should not be ignored in posterior malleolar fractures.

For single fragment fractures (Mason 2A), we choose a posterolateral approach to expose posterior malleolar fragment that needs to be elevated proximally to distally, and then IAIF can be identified and reduced. Finally, posterior malleolar fragment is reduced anatomically, covering IAIF, and fixed with screws. In multifragment fractures (Mason $2 B$ ), a posterolateral approach combined with posteromedial approach and modified posteromedial approach are both options [26, 27]. A modified posteromedial approach is preferred in our institution. Both posterolateral and posteromedial fragments can be exposed through this single straight approach, and posterolateral and posteromedial fragments are elevated from interfragment fracture line to laterally and medially, respectively, named as "opening book." IAIFs in lateral or medial side can then be found and reduced.

There are several limitations in this study. First, the small cohort of patients may affect the accuracy of the results, more patients are required for future research. Second, only the surgery patients are included because CT scans were seldom performed on patients with nondisplaced ankle fractures in our institution. Third, we use the techniques of Mimics Software to measure length and area manually, which are subjective and the results are mainly based on descriptions.

In conclusion, our research indicates a high incidence of IAIF in posterior malleolar fractures. We describe the morphology of posterior malleolar fragments, as well as IAIF, in detail. All IAIFs are found in the posterior malleolar, and the most common location is within the lateral area A. It heralds the incidence of IAIF when posterior malleolar fracture lines extend to medial malleolus or fibular notch. $L_{\mathrm{IFN}} /\left(L_{\mathrm{IFN}}+L_{\mathrm{SFN}}\right), L_{\mathrm{MPMF}}$ and $A_{\mathrm{PMF}}$ are also associated with the incidence of IAIF. IAIF is also helpful to understand the mechanism of posterior malleolar fractures. Our studies indicate that CT scans are most effective for ankle fractures with posterior malleolar fractures in determining the 
occurrence of IAIF and making the operation plan. The choice of a surgical approach is mainly based on the morphology of posterior malleolar fragments and the location of IAIF.

\section{Abbreviations}

IAIF: Intraarticular impacted fragment; $L_{\text {IFN }}$ : Length of involved fibular notch; $L_{\text {SFN }}$ : Length of stable fibular notch; $L_{\text {IAIF }}$ : Length of IAIF; $A_{\text {IAIF }}$ : Area of IAIF; $A_{\text {PMF }}$ Area of posterior malleolar fragment; $A_{\text {STP }}$ : Area of stable tibial plafond; $L_{\text {MPMF }}$ : Length of major posterior malleolar fragment; $L_{\mathrm{ST} p}$ : Length of stable tibial plafond; $H_{\text {IAF: }}$ : Height of IAIF; PAB: Pronation-abduction; PER: Pronation-external rotation; SER: Supination-external rotation; CT: Computed tomography.

\section{Acknowledgements}

We thank BYZ for his support, which is essential for this work.

\section{Authors' contributions}

WYX, HL, and HLX performed data analysis, as well as writing the manuscript. YJL, ZGF, and YQ contributed to the collection of data and manuscript editing. DYZ and BGJ edited the manuscript and were the guarantor of this article. All authors read and approved the integrity and accuracy of the final manuscript. All authors read and approved the final manuscript.

\section{Funding}

This study was approved by the institutional review board of our institution (2020PHB072-01) Funding: (1) Key Laboratory of Trauma and Neural Regeneration (Peking University), Ministry of Education. (2) Capital's Funds for Health Improvement and Research (No. 2020-2-4086). (3) The Beijing Municipal Science and Technology Project, Z181100001718159.

\section{Availability of data and materials}

The datasets used and/or analyzed during the current study are available from the corresponding author on reasonable request.

\section{Declarations}

Ethics approval and consent to participate

This study was approved by the institutional review board of our institution (2020PHB072-01).

\section{Consent for publication}

Not applicable.

\section{Competing interests}

The authors declare that they have no competing interests.

\section{Author details}

'Department of Orthopedics and Trauma, Peking University People's Hospital, Beijing 100044, China. ${ }^{2}$ Trauma Center, National Center for Trauma Medicine, Beijing 100044, China. ${ }^{3}$ Key Laboratory of Trauma and Neural Regeneration, Peking University People's Hospital, Beijing 100044, China.

Received: 17 April 2021 Accepted: 17 November 2021 Published online: 10 December 2021

\section{References}

1. Daly PJ, Fitzgerald RJ, Melton LJ, Ilstrup DM (1987) Epidemiology of ankle fractures in Rochester, Minnesota. Acta Orthop Scand 58(5):539-544

2. Court-Brown CM, McBirnie J, Wilson G (1998) Adult ankle fractures-an increasing problem? Acta Orthop Scand 69(1):43-47

3. Jaskulka RA, Ittner G, Schedl R (1989) Fractures of the posterior tibial margin: their role in the prognosis of malleolar fractures. J Trauma 29(11):1565-1570

4. White TO (2018) In defence of the posterior malleolus. Bone Joint J 100-B(5):566-569
5. Solan MC, Sakellariou A (2017) Posterior malleolus fractures: worth fixing. Bone Joint J 99-B(11):1413-1419

6. Møller BN, Krebs B (1982) Intra-articular fractures of the distal tibia. Acta Orthop Scand 53(6):991-996

7. Hak DJ, Egol KA, Gardner MJ, Haskell A (2011) The "not so simple" ankle fracture: avoiding problems and pitfalls to improve patient outcomes. Instr Course Lect 60:73-88

8. Nwankwo EC, Labaran LA, Athas V, Olson S, Adams SB (2019) Pathogenesis of posttraumatic osteoarthritis of the ankle. Orthop Clin N Am 50(4):529-537

9. Rammelt S, Bartoníček J (2020) Posterior malleolar fractures: a critical analysis review. JBJS Rev 8(8):e1900207

10. Blom RP, Hayat B, Al-Dirini RMA, Sierevelt I, Kerkhoffs GMMJ, Goslings JC, Jaarsma RL, Doornberg JN, EF3X-trial Study Group (2020) Posterior malleolar ankle fractures. Bone Joint J 102-B(9):1229-1241

11. Weber M (2004) Trimalleolar fractures with impaction of the posteromedial tibial plafond: implications for talar stability. Foot Ankle Int 25(10):716-727

12. Scheck M (1962) Long-term follow-up of treatment of comminuted fractures of the distal end of the radius by transfixation with Kirschner wires and cast. J Bone Joint Surg Am 44-A:337-351

13. Sultan F, Zheng X, Pan Z, Zheng Q, Li H, Wang J (2020) Characteristics of intercalary fragment in posterior malleolus fractures. Foot Ankle Surg 26(3):289-294

14. Wang Z, Yuan C, Zhu G, Geng X, Zhang C, Huang J, Ma X, Wang X (2020) A retrospective study on the morphology of posterior malleolar fractures based on a CT scan: whether we ignore the importance of fracture height. Biomed Res Int 2020:2903537

15. Ma T, Zheng X, He XB, Guo KJ (2017) The role of brachioradialis release during $\mathrm{AO}$ type $\mathrm{C}$ distal radius fracture fixation. Orthop Traumatol Surg Res 103(7):1099-1103

16. Lauge-Hansen N (1950) Fractures of the ankle. II. Combined experimental-surgical and experimental-roentgenologic investigations. Arch Surg 60(5):957-985

17. Meinberg EG, Agel J, Roberts CS, Karam MD, Kellam JF (2018) Fracture and dislocation classification compendium-2018. J Orthop Trauma 32(Suppl):1. https://doi.org/10.1097/BOT.0000000000001063

18. Haraguchi N, Haruyama H, Toga H, Kato F (2006) Pathoanatomy of posterior malleolar fractures of the ankle [published correction appears in J Bone Joint Surg Am. 88(8):1835]. J Bone Joint Surg Am 88(5):1085-1092. https://doi.org/10.2106/JBJS.E.00856

19. Mason LW, Marlow WJ, Widnall J, Molloy AP (2017) Pathoanatomy and associated injuries of posterior malleolus fracture of the ankle. Foot Ankle Int 38(11):1229-1235

20. De Vries JS, Wijgman AJ, Sierevelt IN, Schaap GR (2005) Long-term results of ankle fractures with a posterior malleolar fragment. J Foot Ankle Surg 44(3):211-217

21. McDaniel WJ, Wilson FC (1977) Trimalleolar fractures of the ankle. An end result study. Clin Orthop Relat Res 122:37-45

22. Tejwani NC, Pahk B, Egol KA (2010) Effect of posterior malleolus fracture on outcome after unstable ankle fracture. J Trauma 69(3):666-669. https://doi.org/10.1097/TA.0b013e3181e4f81e

23. Vosoughi AR, Jayatilaka MLT, Fischer B, Molloy AP, Mason LW (2019) CT analysis of the posteromedial fragment of the posterior malleolar fracture. Foot Ankle Int 40(6):648-655

24. Gardner MJ, Boraiah S, Hentel KD, Helfet DL, Lorich DG (2007) The hyperplantarflexion ankle fracture variant. J Foot Ankle Surg 46(4):256-260

25. Bartonicek J, Rammelt S, Tucek M, Nanka O (2015) Posterior malleolar fractures of the ankle. Eur J Trauma Emerg Surg 41 (6):587-600

26. Bali N, Aktselis I, Ramasamy A, Mitchell S, Fenton P (2017) An evolution in the management of fractures of the ankle: safety and efficacy of posteromedial approach for Haraguchi type 2 posterior malleolar fractures. Bone Joint J 99-B(11):1496-1501

27. Meyer TL, Kumler KW (1980) A.S.I.F. technique and ankle fractures. Clin Orthop Relat Res 150:211-216

\section{Publisher's Note}

Springer Nature remains neutral with regard to jurisdictional claims in published maps and institutional affiliations. 